\title{
Arachidonic Acid Stimulates a Novel Cocaine-Sensitive Cation Conductance Associated with the Human Dopamine Transporter
}

\author{
Susan L. Ingram and Susan G. Amara \\ Vollum Institute and Howard Hughes Medical Institute, Oregon Health Sciences University, Portland, Oregon 97201
}

The dopamine transporter (DAT) exhibits several ionic currents that are either coupled to or uncoupled from the transport of substrate. Second messenger systems have been shown to modulate dopamine (DA) transport, however, the modulation of DAT-associated currents has not been studied in depth. Using the two-electrode voltage-clamp method to record from Xenopus oocytes expressing the human DAT, we examined the effects of arachidonic acid (AA) on membrane currents. AA $(10-100 \mu \mathrm{M})$ stimulates a novel nonselective cation conductance seen only in oocytes expressing human DA transporter (hDAT). The AA-stimulated conductance is up to 50-fold greater than the current normally elicited by DA, but does not appear to arise from the modulation of previously described hDAT conductances, including the leak current and the current associ- ated with electrogenic transport. In addition, DA dramatically potentiates and cocaine blocks the AA-stimulated DAT current. DA potentiates the AA-induced currents in the absence of sodium and chloride, indicating that these currents arise from processes distinct from those associated with substrate transport. The effects of AA were mimicked by other fatty acids with a rank order of potency correlated with their degree of unsaturation, suggesting that $A A$ directly stimulates the novel cation current. Therefore, AA stimulation of this DAT-associated conductance may provide a novel mechanism for modulation of neuronal signaling.

Key words: dopamine; transporters; cocaine; nonselective cation channels; arachidonic acid; fatty acids
The dopamine transporter (DAT) serves to regulate extracellular DA concentrations and terminate the action of DA in the synapse. DAT is a member of the $\mathrm{Na}^{+} / \mathrm{Cl}^{-}$-dependent neurotransmitter transporter family, is localized to dopamine (DA) neurons, and is the principal site of action for cocaine and other psychomotor stimulants. Electrophysiological studies of the cloned biogenic amine transporters have provided insight into mechanisms of substrate and ion permeation reflecting different aspects of the function of the carrier by demonstrating that these transporters mediate several ionic currents (for review, see Lester et al., 1994; DeFelice and Blakely, 1996; Sonders and Amara, 1996). Currents identified in the human DA transporter (hDAT) include a transport current reflecting substrate movement, transient currents associated with $\mathrm{Na}^{+}$binding, and a tonic leak conductance that can be blocked by substrates and substrate inhibitors (Sonders et al., 1997).

Many lines of evidence suggest that DAT can be acutely regulated. For example, DAT has been shown to be modulated by activation of D2 receptors (Meiergerd et al., 1993; Cass and Gerhardt, 1994), protein kinase C (Zhang et al., 1997; Zhu et al., 1997), nitric oxide (Pogun et al., 1994; Itzhak and Ali, 1996), and arachidonic acid (AA) (L'hirondel et al., 1995; Zhang and Reith, 1996). Arachidonic acid modulates ion channels and transporters in two ways: via direct binding to proteins and through second messenger actions of AA metabolites produced by lipoxygenases, cyclooxygenases, and epoxygenases (for review, see Ordway et al.,

Received July 16, 1999; revised Oct. 15, 1999; accepted Oct. 22, 1999.

This work was supported by the Howard Hughes Medical Institute and National Institutes of Health Grant DAO7595.We thank W. Fairman and Drs. K. Poth, B. Prasad, and M. Sonders for discussion and critical reading of this manuscript.

Correspondence should be addressed to Susan G. Amara, Vollum Institute and Howard Hughes Medical Institute, L-474, Oregon Health Sciences University, 3181 SW Sam Jackson Park Road, Portland, OR 97201. E-mail: amaras@ohsu.edu. Copyright (C) 2000 Society for Neuroscience $0270-6474 / 00 / 200550-08 \$ 15.00 / 0$
1991; Attwell et al., 1993). The generation of AA in the striatum, an area with dense immunohistochemical staining for DAT (Ciliax et al., 1995; Nirenberg et al., 1996), is stimulated by excitatory amino acids (Dumuis et al., 1988; Dumuis et al., 1990; Petitet et al., 1995; Tencé et al., 1995). Many experiments have observed an interaction between the DA and AA signaling pathways. Stimulation of $\mathrm{D} 2$ receptors increases the production of $\mathrm{AA}$ in striatal neurons (Piomelli et al., 1991; Schinelli et al., 1994), and DA transport by DAT can be modulated by AA (L'hirondel et al., 1995; Zhang and Reith, 1996). In addition, AA has been shown to modulate both transport of glutamate (Chan et al., 1983; Volterra et al., 1992b; Volterra et al., 1994; Trotti et al., 1995) and conductances associated with glutamate transporters (Barbour et al., 1989; Zerangue et al., 1995; Fairman et al., 1998; Tzingounis et al., 1998). To gain a better molecular understanding of how DAT can be regulated by AA, we examined the effects of AA and other polyunsaturated fatty acids on both the currents and transport activity of the cloned hDAT expressed in Xenopus laevis oocytes. Here we show that AA stimulates a novel nonselective cation conductance that is potentiated by dopamine and blocked by preapplication of cocaine.

\section{MATERIALS AND METHODS}

hDAT expression in oocytes. Capped RNA was transcribed from linearized pOTV-hDAT using T7 RNA polymerase (mMessage mMachine, Ambion, Austin, TX) as described by Sonders et al. (1997). The RNA was diluted with water and injected into defolliculated stage IV or V oocytes ( $\sim 10 \mathrm{ng} /$ oocyte). The oocytes were prepared as described by Quick and Lester (1994) and kept at $17^{\circ} \mathrm{C}$ for $4-8 \mathrm{~d}$.

Electrophysiology. Two-microelectrode voltage-clamp recordings were performed at room temperature using a GeneClamp 500 amplifier with a Digidata 1200 interface (Axon Instruments, Foster City, CA). The pClamp6 suite of programs (Axon Instruments) and MacLab (AD Instruments, Milford, MA) were used to control stimulation parameters and data acquisition. Currents were low-pass filtered between 10 and 2 

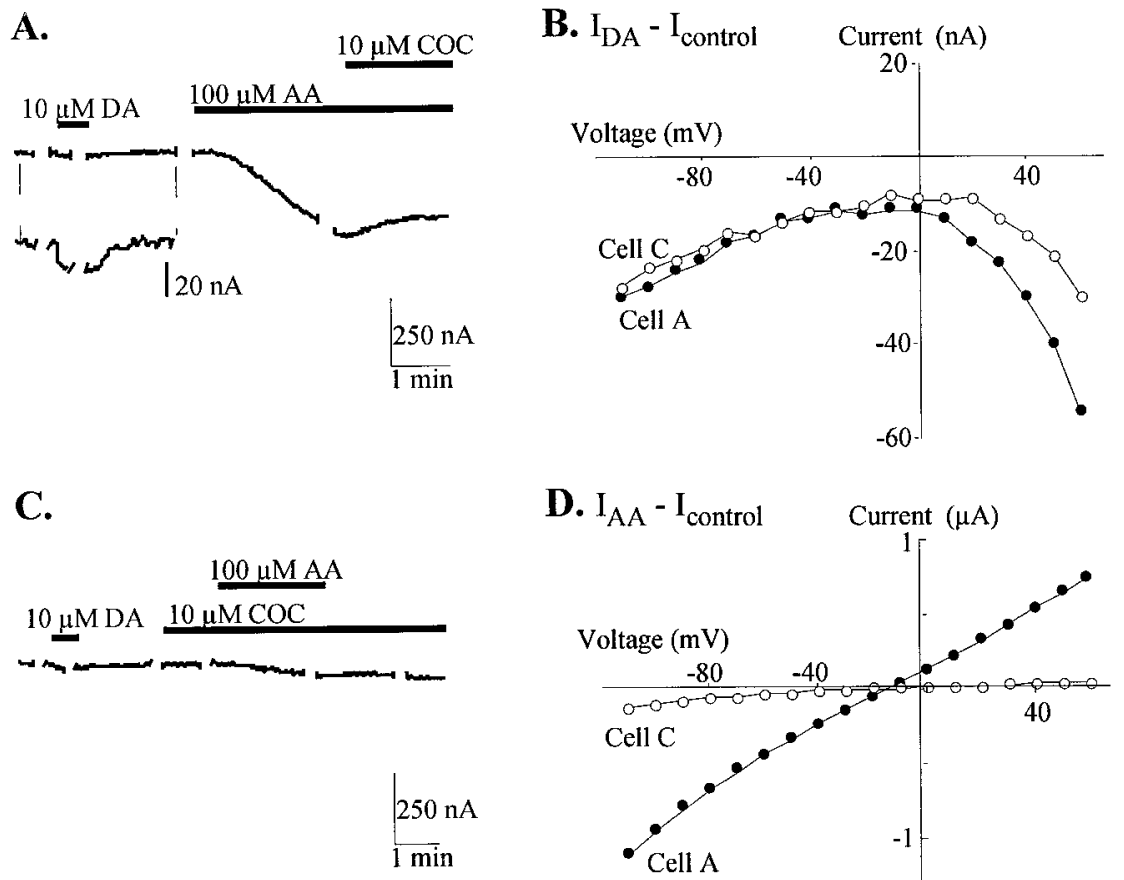

D. $I_{A A}-I_{\text {control }}$

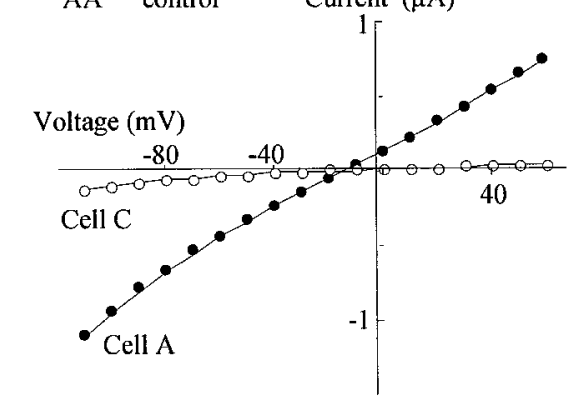

E.

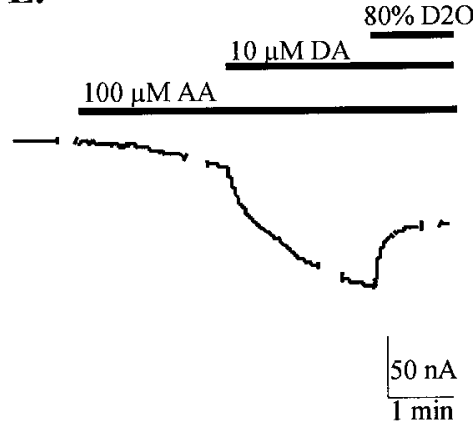

F.

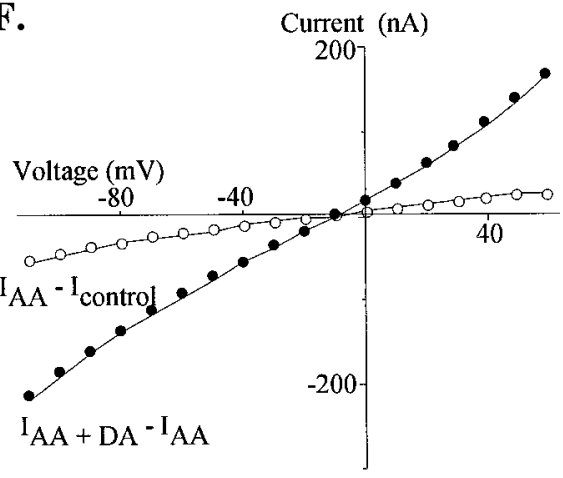

Figure 1. DA and AA stimulate inward currents in hDAT-expressing oocytes. $A$, Representative trace from an oocyte held at $-60 \mathrm{mV}$. Breaks in traces denote where voltage steps were done for $I-V$ curves. Drug superfusion is denoted by bars. Cocaine has a minimal effect on the AA-stimulated conductance. Inset shows an expanded scale for the response to DA. $B$, Current-voltage plots comparing $I_{\mathrm{DA}}-I_{\text {control }}$ responses from cell A (closed circles) and cell C (open circles). $C$, Trace from an oocyte held at $-60 \mathrm{mV}$ showing the AA response after preapplication of cocaine. $D$, Comparison of current-voltage plots for $I_{\mathrm{AA}}-I_{\text {control }}$ in the absence (closed circles; cell A) and presence (open circles; cell C) of cocaine. E, DA potentiates the AA current, and the elicited current is partially blocked by addition of $80 \% \quad \mathrm{D}_{2} \mathrm{O}$ external solution, $\mathrm{pH}$ 7.9. $F, I-V$ plots of $I_{\mathrm{AA}}-I_{\text {control }}$ (open circles) and $I_{\mathrm{AA}}+\mathrm{DA}-I_{\mathrm{AA}}$ (closed circles) from $E$. Note the same reversal potential for both currents.
$\mathrm{kHz}$ and digitized at rates between 1 and $5 \mathrm{kHz}$. Microelectrodes were filled with $3 \mathrm{M} \mathrm{KCl}$ (resistance, $<1 \mathrm{M} \Omega$ ). The frog Ringer's external solution $\left(0 \mathrm{Ca}^{2+}\right)$ contained (in $\left.\mathrm{mM}\right): 96 \mathrm{NaCl}, 2 \mathrm{KCl}, 3 \mathrm{MgCl}_{2}$, and 5 HEPES-NaOH, $\mathrm{pH} 7.5$, or substituted versions as specified. During $\mathrm{Cl}^{-}$ substitutions, $\mathrm{KCl} /$ agar bridges were used to avoid voltage offsets associated with buffer changes. Glass electrodes underestimate deuterium ion concentration, therefore in $\mathrm{D}_{2} \mathrm{O}$ experiments, Ringer's solution was adjusted to an apparent $\mathrm{pH}$ that is $0.4 \mathrm{pH}$ units greater than normal $\mathrm{pH}$ to maintain equimolar concentrations of deuterons and protons.

The voltage dependence of hDAT currents were studied using the following voltage protocol: oocytes were held at $-60 \mathrm{mV}$ and stepped by $10 \mathrm{mV}$ increments for $500 \mathrm{msec}$ to test potentials ranging from -110 to $+60 \mathrm{mV}$. Steady-state currents were measured at the end of each test potential jump. Agonist-elicited currents were determined by subtracting control trials from the drug trials $\left(I_{\text {drug }}-I_{\text {control }}\right)$. Currents induced by DA $(10 \mu \mathrm{M})$ were small (5-20 nA) but measurable and reversible. AA-induced currents were much larger and often reached steady-state in 2-4 min. The amplitude of the AA-elicited current varied between oocytes within batches and to a larger extent from batch to batch. The AA-elicited current typically did not wash out to control levels in the normal course of an experiment ( $30 \mathrm{~min}$ to $1 \mathrm{hr}$ ), although $0.1-1 \%$ BSA accelerated the partial reversal of AA effects (data not shown; $n=5$ ). Long-lasting effects of AA have also been observed with direct AA modulation of ion channels (Schmitt and Meves, 1995). In some cases, longer applications of higher concentrations of AA $(100 \mu \mathrm{M})$ induced inward currents $(>5 \mu \mathrm{A})$ that never reached steady-state, presumably because of the formation of micelles (Attwell et al., 1993). Thus, elec- trophysiological experiments were confined to short applications of AA, and uptake experiments in this study were confined to $2 \mathrm{~min}$ in AA and 2 min in AA $+\left[{ }^{3} \mathrm{H}\right] \mathrm{DA}$. In hDAT-expressing oocytes, DA stimulates a membrane conductance that has a complex current-voltage relationship because it reflects both the current associated with translocation of DA and the block of a tonic proton leak (Fig. $1 B$ ). The current elicited in the range of -40 to $-100 \mathrm{mV}$ reflects the transport-associated conductance but may be underestimated because of simultaneous block of the leak current. Measurements of the DA-stimulated conductance were taken as the slope of the conductance between -40 and $-100 \mathrm{mV}$.

Drugs were obtained from National Institute on Drug Abuse Research (Bethesda, MD) or were purchased from Research Biochemicals (Natick, MA) or Sigma (St. Louis, MO). Test compounds were made up as 100 mM stock solutions in either DMSO or ethanol $(\mathrm{EtOH})$ and stored at $-80^{\circ} \mathrm{C}$. Immediately before use the drugs were dissolved into Ringer's solution at the indicated concentrations. No significant currents were induced by $0.1 \% \mathrm{DMSO}$ or $0.1 \% \mathrm{EtOH}$ in either water-injected control oocytes or hDAT-expressing oocytes.

Uptake assays. Uptake assays were done at room temperature using the frog Ringer's solution described above. Groups of oocytes (four to six) were preincubated in the specified buffer (in presence or absence of ligands indicated) for 2 min. The uptake assays commenced with the addition of $\left[{ }^{3} \mathrm{H}\right] \mathrm{DA}$ (NEN, Boston MA; specific activity, $55.5 \mathrm{Cii} / \mathrm{mmol}$ ) to a final volume of $500 \mu \mathrm{l}$ for a 2 min incubation and terminated by transferring the oocytes through a series of three washes in ice-cold Ringer's buffer (total transfer time, $<20 \mathrm{sec}$ ). Nonspecific uptake was determined by performing parallel experiments with $\mathrm{H}_{2} 0$-injected oo- 
cytes. The velocity of DA uptake has been shown to be essentially constant over incubation periods between 0.5 and 60 min using 75-200 nM $\left[{ }^{3}\right.$ H]DA (Sonders et al., 1997). Saturation experiments used at least eight DA concentrations between $10 \mathrm{nM}$ and $300 \mu \mathrm{M}$. Radiolabeled DA was quantified by liquid scintillation spectroscopy $(5 \mathrm{ml}$; ScintiVerse; Fisher, Pittsburgh, PA) after dissolving individual oocytes in $250 \mu \mathrm{l}$ of $0.1 \%$ SDS. Uptake data are represented as normalized percentage of control uptake at $\mathrm{pH}$ 7.5. Apparent affinity $\left(K_{\mathrm{T}}\right)$ and $V_{\max }$ values were estimated by nonlinear regression analysis to the equation $V / V_{\max }=$ $[S] /\left(K_{\mathrm{T}}+[S]\right)$ where $V$ equals velocity, $K_{\mathrm{T}}$ is the Michaelis constant for transport, and $[S]$ denotes concentration of substrate.

$D A$ uptake under voltage-clamp. DA uptake was measured under voltage-clamp at $-60 \mathrm{mV}$ by liquid scintillation spectroscopy after $5 \mathrm{~min}$ perfusions of $11 \mu \mathrm{M}$ DA $\left(1 \mu \mathrm{M}\left[{ }^{3} \mathrm{H}\right] \mathrm{DA}\right.$; Amersham, Piscataway NJ; specific activity, $5.9 \mathrm{Cii} / \mathrm{mmol})$. After incubations with DA, oocytes were washed for $1 \mathrm{~min}$ with frog Ringer's solution, the voltage clamp was turned off, electrodes were withdrawn, and individual oocytes were transferred to SDS solution and treated as described above. Experiments were done in the absence and presence of AA $(100 \mu \mathrm{M})$ with nonspecific uptake defined as uptake under clamped conditions in $\mathrm{H}_{2} \mathrm{O}$-injected oocytes.

\section{RESULTS}

\section{Arachidonic acid stimulates an inward current in oocytes expressing hDAT}

The effects of AA on the electrophysiological properties of hDAT expressed in Xenopus laevis oocytes were examined using the two-electrode voltage-clamp technique. In hDAT-expressing oocytes voltage-clamped at $-60 \mathrm{mV}$, superfusion of arachidonic acid (1-100 $\mu \mathrm{M})$ stimulated a concentration-dependent inward current that was up to 50-fold larger in amplitude than the current induced by translocation of $10 \mu \mathrm{M}$ DA (Fig. $1 A)$. DA $\left(I_{\mathrm{DA}}-I\right.$ control) elicited a current with a slope for the transport-associated component of $0.23 \pm .06 \mu \mathrm{S}$. The slope of the conductance induced by $10 \mu \mathrm{M}$ AA $\left(I_{\mathrm{AA}}-I_{\text {Control }}\right)$ in the same oocytes was $1.2 \pm 0.4 \mu \mathrm{S}$ and by $100 \mu \mathrm{M}$ AA was $6.6 \pm 2.3 \mu \mathrm{S}(n=4)$. AA did not elicit a similar current in matched batches of $\mathrm{H}_{2} \mathrm{O}$-injected oocytes, suggesting that hDAT expression is necessary to elicit this current $(n=6)$. Unlike the DA-induced current that does not reverse because DA also blocks the leak conductance (Fig. 1B), the AA-stimulated current was ohmic and reversed at $-16 \pm 2$ $\mathrm{mV}(n=6$; Fig. $1 D)$.

\section{AA-stimulated conductance is directly associated with DAT}

Cocaine, an inhibitor of substrate translocation by DAT, does not stimulate an inward transport-associated current but has been shown to inhibit a proton-selective leak conductance through hDAT (Sonders et al., 1997). Surprisingly, application of cocaine did not block the AA-stimulated conductance once it had been elicited $(13 \pm 5 \%$ inhibition; $n=5$; Fig. $1 A)$. However, preapplication of cocaine $(10 \mu \mathrm{M})$ inhibited the induction of AA currents (Fig. 1C). The slopes of the conductances elicited by $10 \mu \mathrm{M}$ AA were much smaller in the presence of cocaine $(0.32 \pm 0.1 \mu \mathrm{S}$; $n=4)$ than in the absence of cocaine $(1.4 \pm 0.3 \mu \mathrm{S} ; n=8$; Fig. $1 C, D)$. These results suggest that AA modulates a conductance associated with DAT.

DA dramatically alters the steady-state current response to AA. DA applied in the presence of AA stimulates a larger conductance than either DA or AA alone (Fig. $1 E, F$ ). In a group of oocytes, DA $(10 \mu \mathrm{M})$ induced an inward current $\left(I_{\mathrm{DA}}-I_{\text {control }}\right)$ with a slope of $0.34 \pm 0.1 \mu \mathrm{S}(n=12)$. In a subset of these oocytes, DA was washed out, and the AA $(10 \mu \mathrm{M})$ response was recorded and in the other subset; AA and DA were coapplied. Larger inward currents were elicited by AA in the presence of DA $\left(I_{\mathrm{DA}}+\mathrm{AA}-I_{\text {control }}: 3.8 \pm 0.8 \mu \mathrm{S} ; n=4\right)$ than in the absence of
DA $\left(I_{\text {AA }}-I_{\text {control }}: 1.4 \pm 0.3 \mu \mathrm{S} ; n=8\right)$. Interestingly, DA had a larger stimulatory effect on the AA current when applied during AA superfusion $\left(I_{\mathrm{AA}}+\mathrm{DA}-I_{\text {control }}: 6.7 \pm 1.5 \mu \mathrm{S} ; n=7\right)$ than when AA was applied in the presence of DA. This effect was also apparent when AA $(100 \mu \mathrm{M})$ was superfused in the absence (42 \pm $8 \mu \mathrm{S} ; n=6)$ and presence of DA $(83 \pm 14 \mu \mathrm{S} ; n=6)$. There was no effect of the combination of AA and DA on $\mathrm{H}_{2} \mathrm{O}$-injected control oocytes $(n=10)$.

The currents elicited by AA in the absence and presence of DA were not changed by the addition of inhibitors of endogenous ion exchangers, further supporting the idea that the cation conductance is directly associated with DAT. In a series of experiments AA $(100 \mu \mathrm{M})$ was superfused in the presence of DA (slope $=$ $66 \pm 10 \mu \mathrm{S} ; n=7)$. The slope conductances $\left(I_{\mathrm{AA}}+\mathrm{DA}-I_{\text {control }}\right)$ were not changed by amiloride $(100 \mu \mathrm{M})$, an inhibitor of the $\mathrm{Na}^{+} / \mathrm{H}^{+}$exchanger $(108 \pm 20 \% ; n=4)$, furosemide $(100 \mu \mathrm{M}$; $92 \pm 33 \% ; n=4)$, or bumetanide $(100 \mu \mathrm{M} ; 115 \pm 11 \% ; n=4)$, inhibitors of the $\mathrm{Na}^{+} / \mathrm{K}^{+} / 2 \mathrm{Cl}^{-}$exchanger, or ouabain, an inhibitor of the $\mathrm{Na}^{+} / \mathrm{K}^{+}$-ATPase $(100 \mu \mathrm{M} ; 123 \pm 14 \% ; n=5)$.

\section{AA does not modulate the leak conductance associated with hDAT}

In a distinct subfamily of $\mathrm{Na}^{+}$-coupled carriers for excitatory amino acids, AA was recently demonstrated to stimulate a proton conductance through the glutamate transporter EAAT4 (Fairman et al., 1998; Tzingounis et al., 1998). Because hDAT has a proton-selective leak conductance, it was possible that an increase in this constitutive leak underlies the AA-enhanced conductance. Although increasing the proton concentration over the range $\mathrm{pH}$ 8.3 to $\mathrm{pH} 6.8$ diminished the amplitude of the AA-elicited current, the reversal potential was not changed, indicating that protons do not carry the AA-elicited current (Fig. $2 A, B$ ). In contrast, the inhibitory effect of protons on the current magnitude suggests that a protonatable amino acid in hDAT can influence the permeation of other ions. Experiments using heavy water $\left(\mathrm{D}_{2} \mathrm{O}\right)$ provided further support for this idea. When applied to hDATexpressing oocytes, external $\mathrm{D}_{2} \mathrm{O}$ reduced the amplitude but did not alter the reversal potential of the AA-elicited current $(n=13$; data not shown). In addition, as shown in Figure $1 E, \mathrm{D}_{2} \mathrm{O}$ could block a portion of the AA-elicited current, consistent with the fact that deuterons bind with higher affinity than protons.

\section{DA potentiates the AA-induced current}

Our results have demonstrated that AA stimulates an inward current that is inhibited by cocaine and potentiated by DA and does not appear to be the proton leak conductance through DAT. There are at least two interpretations of the synergistic effects of AA + DA. Either AA stimulates the transport-associated component of the DA conductance or DA has a modulatory effect on the AA-induced conductance in hDAT-expressing oocytes. Uptake experiments were performed to address whether the conductance modulated by AA reflects the substrate translocation process through hDAT (Fig. $2 C$ ). Changing $\mathrm{pH}$ in the range of $\mathrm{pH} 6.8$ to $\mathrm{pH} 8.3$ had only minor effects on the uptake of $75 \mathrm{~nm}\left[{ }^{3} \mathrm{H}\right] \mathrm{DA}$ into hDAT-expressing oocytes. Additionally, application of 100 $\mu \mathrm{M}$ AA at any $\mathrm{pH}$ did not increase transport of $\left[{ }^{3} \mathrm{H}\right] \mathrm{DA}$ relative to control uptake at $\mathrm{pH}$ 7.5. The DA transport affinity also appears to be unaltered, as demonstrated by experiments showing that AA $(100 \mu \mathrm{M})$ did not change the apparent affinity $\left(\mathrm{K}_{\mathrm{T}}\right)$ for transport (control $\mathrm{K}_{\mathrm{T}}=2.2 \pm 0.8 \mu \mathrm{M}$ compared to $\mathrm{AA} \mathrm{K}_{\mathrm{T}}=$ $3.1 \pm 0.6 \mu \mathrm{M} ; n=4$ experiments). The apparent $V_{\max }$ was slightly increased over control in the presence of $100 \mu \mathrm{M} \mathrm{AA}(49 \pm 15 \%)$. 

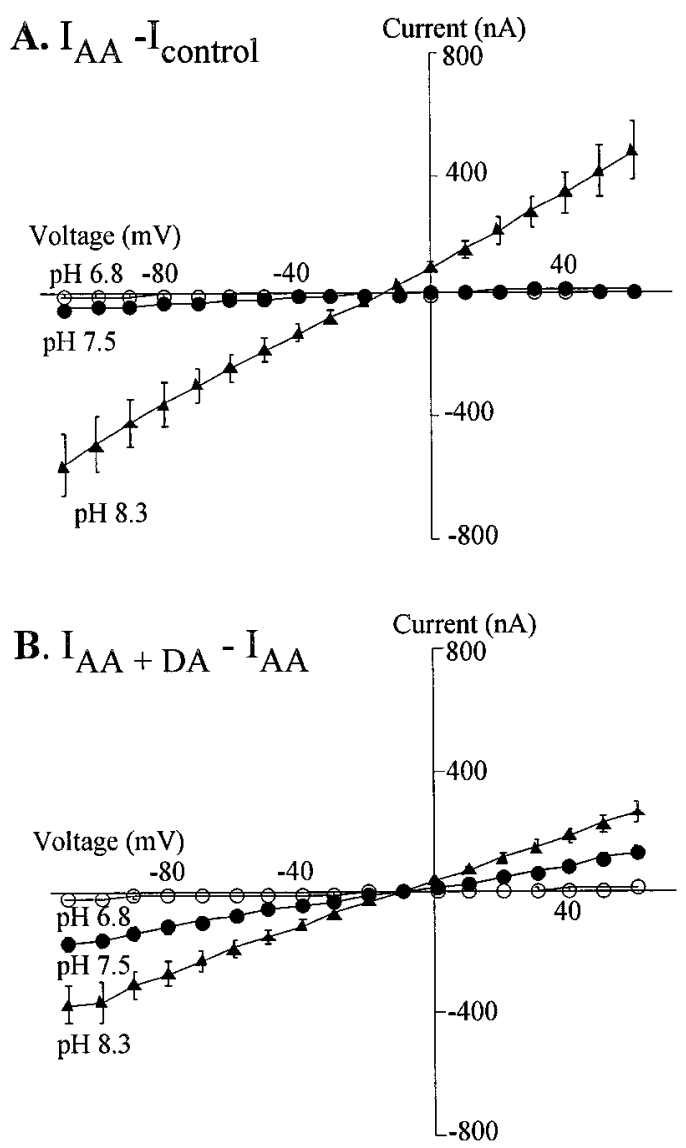

C.

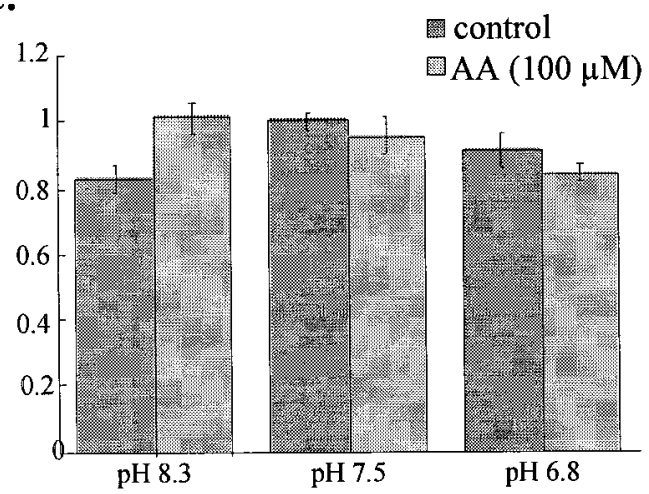

Figure 2. Effect of pH on AA $(100 \mu \mathrm{M})$ and AA + DA $(10 \mu \mathrm{M})$ stimulated currents. $A$, Current-voltage plots for combined oocytes (mean $\pm \mathrm{SEM})$ for subtracted traces $I_{\mathrm{AA}}-I_{\text {control }}$ in normal external solution (ND96) at $\mathrm{pH} 6.8$ (open circles; $n=3$ ), $\mathrm{pH} 7.5$ (closed circles; $n=$ 8 ), and $\mathrm{pH} 8.3$ (closed triangles; $n=5$ ). $B$, Current-voltage plots are shown for subtracted currents $I_{\mathrm{AA}}+\mathrm{DA}-I_{\mathrm{AA}}$ in normal ND96 with different $\mathrm{pH}$ values in same cells as in $A$. $C$, Mean uptake of $75 \mathrm{nM}\left[{ }^{3} \mathrm{H}\right] \mathrm{DA}$ in the absence (dark bars) and presence (light bars) of AA $(100 \mu \mathrm{M})$. Uptake is normalized to the mean control uptake at $\mathrm{pH} 7.5$ for four experiments with four to six oocytes per experiment. Nonspecific uptake was determined by running parallel uptake experiments on $\mathrm{H}_{2} \mathrm{O}$-injected control oocytes.

However, when uptake assays were performed on oocytes held at $-60 \mathrm{mV}$, AA $(100 \mu \mathrm{M})$ decreased DA uptake from $1.97 \pm 0.30$ $\mathrm{pmol} / \mathrm{min}(n=4)$ to $0.33 \pm 0.12 \mathrm{pmol} / \mathrm{min}(n=4)$, providing clear evidence that AA does not increase the transport-associated component of the DA conductance.

\section{AA stimulation of the cation conductance does not require $\mathrm{Na}^{+}$ions}

Although AA does not seem to alter DA transport, AA may augment the transport-associated current by changing the stoichiometry of ions coupled to the transport mechanism. Ion substitution studies were done to determine the ion selectivity of the AA and AA + DA-stimulated conductances (Fig. 3). Substitution of choline $(100 \mathrm{~mm})$ for $\mathrm{Na}^{+}$did not change the slopes of the AA-stimulated conductances, but shifted the reversal potentials toward the potassium equilibrium potential (approximately -95 $\mathrm{mV}$ in oocytes; Costa et al., 1989). In $\mathrm{Na}^{+}$-containing external solution, AA $(10 \mu \mathrm{M})$ induced a current with a slope of $1.7 \pm 0.4$ $\mu \mathrm{S}$ that reversed at $-21 \pm 2 \mathrm{mV}$ (Fig. $3 B ; n=5$ ). In cholinesubstituted external solution, the AA-induced current had a slope of $2.1 \pm 0.7 \mu \mathrm{S}$ that reversed at $-63 \pm 3 \mathrm{mV}$ (Fig. $3 C ; n=4$ ). These observations indicate that the AA-stimulated current is a nonselective cation conductance observed even in the absence of DA transport (i.e., in $100 \mathrm{~mm}$ choline, $0 \mathrm{~mm}$ sodium). In addition, when taken in conjunction with data in Table 1, these data indicate that both low $(10 \mu \mathrm{M})$ and high $(100 \mu \mathrm{M})$ concentrations of AA stimulate the same conductance.

Substitutions of other bulky cations, i.e., $\mathrm{NMDG}^{+}$and $\mathrm{TEA}^{+}$, also shift the reversal potentials of the AA-elicited conductances toward the potassium equilibrium potential and have little effect on the slopes of the conductances, suggesting only slight differences in permeability relative to choline (Table 1). Replacement of $\mathrm{Na}^{+}$ions with larger cations did not shift the reversal potentials entirely to the potassium equilibrium potential, and thus it was possible that $\mathrm{Cl}^{-}$ions might contribute to the AA-stimulated conductance. However, substitution for $\mathrm{Cl}^{-}$of the less permeable anion, gluconate, and the more permeable anion, isethionate, did not change the reversal potential or the slope conductance of the AA-stimulated current (Table 1). In addition, when $\mathrm{Na}^{+}$is replaced by lithium or potassium, which does not support DA transport but can permeate through cation conductances, comparable or larger AA-elicited conductances are observed (Table 1). These substitutions support the hypothesis that $\mathrm{Na}^{+}$and $\mathrm{Cl}^{-}$ ions are not required to gate the AA-elicited conductance and that this conductance is probably not associated with the transport process.

The substitution series shown in Table 1 was repeated for the conductance stimulated in the presence of both AA and DA $\left(I_{\text {AA }}\right.$ + DA $\left.-I_{\text {control }}\right)$. Substitutions of less permeant cations for $\mathrm{Na}^{+}$ still shifted the reversal potential toward the potassium equilibrium potential, although not to the same extent as for the AA current alone, indicating a slight change in the relative permeability of $\mathrm{Na}^{+}$to $\mathrm{K}^{+}$ions. The slopes of the AA-elicited conductances were significantly greater in the presence of DA, suggesting the possibility that DA produces a conformational change resulting in a larger pore or an increased open probability of the conductance. These results are consistent with the interpretation that both the AA-induced current $\left(I_{\mathrm{AA}}-I_{\text {control }}\right)$ and the current in the presence of both AA and DA $\left(I_{\mathrm{AA}}+\mathrm{DA}-I_{\text {control }}\right)$ are both nonselectively permeable to cations and that DA potentiates the AA-induced current in hDAT-expressing oocytes. Furthermore, it is clear that DA still has effects on hDAT-associated conductances in the absence of $\mathrm{Na}^{+}$ions.

\section{The actions of arachidonic acid are direct}

AA can produce its actions through direct binding to proteins, via metabolites of the AA second messenger system, activation of protein kinase $\mathrm{C}(\mathrm{PKC})$, or increasing membrane fluidity (for 

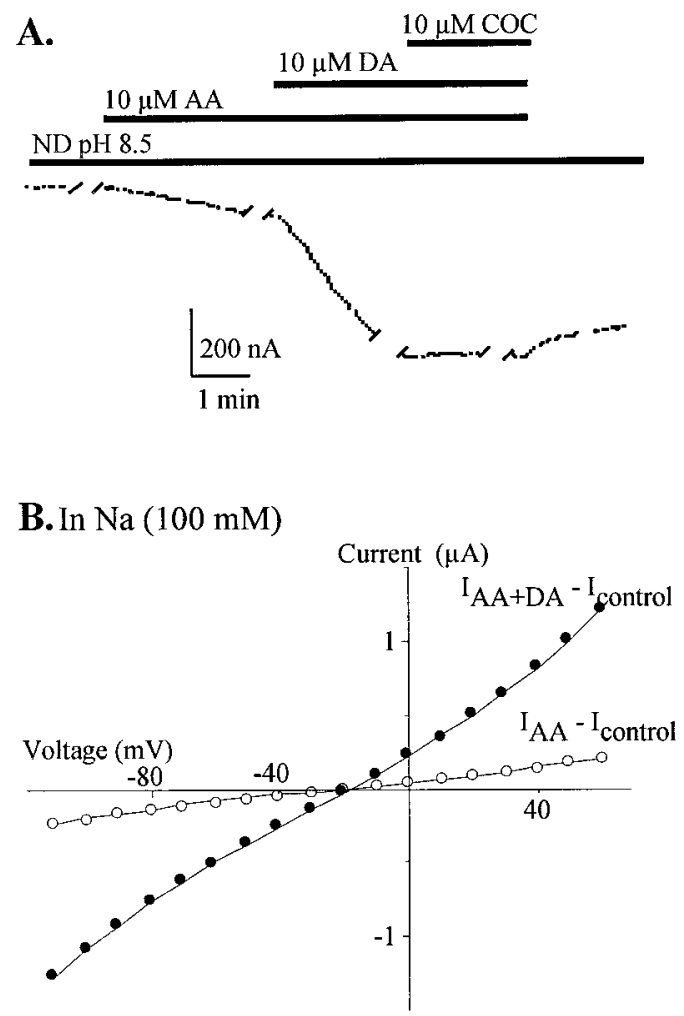

C. In choline (100 mM)

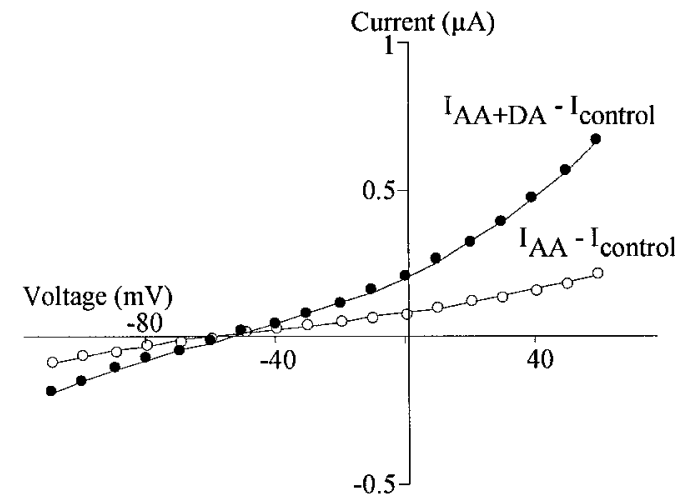

Figure 3. AA stimulates a nonselective cation current in hDATexpressing oocytes. $A$, Representative trace from an oocyte held at -60 $\mathrm{mV}$. Breaks in traces denote where current-voltage steps were made. Drug superfusion is denoted by bars. Note that cocaine does not block DA potentiation of AA current. $B$, Current-voltage plots for the same cell as in $A$. $I-V$ relation for $10 \mu \mathrm{M}$ AA determined by subtraction of currents $I_{\mathrm{AA}}-I_{\text {control }}$ (open circles) and for $10 \mu \mathrm{M} \mathrm{DA}$ in the presence of $10 \mu \mathrm{M} \mathrm{AA}$ $\left(I_{\mathrm{AA}}+\mathrm{DA}-I_{\text {control }}\right.$; closed circles $) . C$, Effect of choline substitution on the currents evoked by AA and DA. Choline substitution shifts the reversal potential for $I_{\mathrm{AA}}-I_{\text {control }}$ (open circles) and $I_{\mathrm{AA}}+\mathrm{DA}-I_{\text {control }}$ (closed circles) toward the potassium equilibrium potential.

review, see Attwell et al., 1993). In hDAT-expressing oocytes, several fatty acids stimulate the inward current similarly to AA with a rank order of potency based on the degree of their unsaturation (docosahexaenoic acid $=\mathrm{AA}>$ linoleic acid $>$ oleic acid) (Fig. 4). Docosahexaenoic acid, which does not activate $\mathrm{PKC}$, is a potent activator of a nonselective cation conductance in hDAT-expressing oocytes. Arachidonic acid ethyl ester, an inactive analog of AA that has similar effects on membrane fluidity, did not stimulate a significant inward current at $-60 \mathrm{mV}(-2 \pm$ $0.9 \mathrm{nA} ; n=4$ ) in oocytes that subsequently demonstrated large current responses to AA. These results suggest that AA is not acting through a nonspecific effect on membrane fluidity. None of these fatty acids produced similar currents in $\mathrm{H}_{2} \mathrm{O}$-injected control oocytes $(n=8)$.

Additional experiments demonstrate that metabolites of AA do not seem to be involved. Nordihydroguaiaretic acid (NDGA), a lipoxygenase inhibitor, does not block the AA or AA + DAinduced conductances. AA $(100 \mu \mathrm{M})$ elicited currents in the presence of NDGA $(100 \mu \mathrm{M})$ with slopes of $41 \pm 7 \mu \mathrm{S}\left(I_{\mathrm{AA}}-\right.$ $\left.I_{\text {control }} ; n=5\right)$ and $93 \pm 13 \mu \mathrm{S}\left(I_{\mathrm{AA}+\mathrm{DA}}-I_{\text {control }} ; n=5\right)$ compared to slopes for AA in the absence of NDGA of $28 \pm 4 \mu \mathrm{S}$ and $64 \pm 6 \mu \mathrm{S}$, respectively $(n=5)$. The nonmetabolizable AA analog 5,8,11,14-eicosatetraynoic acid (ETYA) $(10 \mu \mathrm{M})$ produced similar inward currents to $10 \mu \mathrm{M}$ AA $(1.5 \pm 0.6 \mu \mathrm{S}, n=8$ compared to $1.4 \pm 0.3 \mu \mathrm{S}, n=8$, respectively), and there was no change in the reversal potential of the currents $(-27 \pm 6 \mathrm{mV}$ compared to $-23 \pm 2 \mathrm{mV}$, respectively). In addition, ETYA (10 $\mu \mathrm{M})$ did not block AA $(10 \mu \mathrm{M})$-induced currents $(1.1 \pm 0.2 \mu \mathrm{S}$; $n=4)$ or AA + DA currents $(3.6 \pm 0.4 \mu \mathrm{S} ; n=4)$. Thus, these results suggest that the arachidonic acid metabolites are not involved in the modulation of hDAT but rather there is a direct action of fatty acids on hDAT.

\section{DISCUSSION}

Several lines of evidence demonstrate that the nonselective cation conductance activated by AA in hDAT-expressing oocytes is directly linked to DAT. The AA-induced conductance is potentiated by dopamine, inhibited by previous application of cocaine and not observed in $\mathrm{H}_{2} \mathrm{O}$-injected control oocytes. However, this AA-induced current does not correspond to any of the currents previously shown to be associated with hDAT expression. Biochemical studies have predicted that the DA transport-associated current arises from the stoichiometric coupling of two $\mathrm{Na}^{+}$cotransported and one $\mathrm{Cl}^{-}$countertransported to each molecule of DA transported (Krueger, 1990; Kilty et al., 1991; McElvain and Schenk, 1992; Gu et al., 1994). Charge to flux measurements of hDAT by Sonders et al. (1997) clearly showed that the currents elicited by DA are too large to be accounted for by a stoichiometry where two net inward charges are moved per DA molecule. Therefore, it was postulated that DA transport is associated with both stoichiometrically coupled and uncoupled conductances that are dependent on $\mathrm{Na}^{+}$ions. In the current study AA does not stimulate these transport-associated conductances but instead elicits a large $\mathrm{Na}^{+}$-independent conductance. The amplitude of this AA-activated conductance is 20- to 50-fold larger than the DA-elicited current and cannot be explained by the modest increase in transport $V_{\text {max }}$ that was observed in the presence of AA in unclamped oocytes. In addition, AA decreased uptake of DA in oocytes clamped at $-60 \mathrm{mV}$, providing clear evidence that the AA-stimulated conductance is not the transport-associated conductance. AA inhibition of DA uptake has been observed in several other studies (L'hirondel et al., 1995; Zhang and Reith, 1996; Zhu et al., 1997). Finally, the AA-stimulated conductance does not shift reversal potential in solutions where external $\mathrm{pH}$ is varied from $\mathrm{pH} 6.8$ to $\mathrm{pH} 8.3$, suggesting that AA does not modulate the proton leak current blocked by substrates and substrate inhibitors (Sonders et al., 1997). When the transport and electrophysiological data are taken together, the evidence is consistent with the hypothesis that AA stimulates a novel conductance associated with DAT. 
Table 1. External ion substitution effects on current-voltage relationships

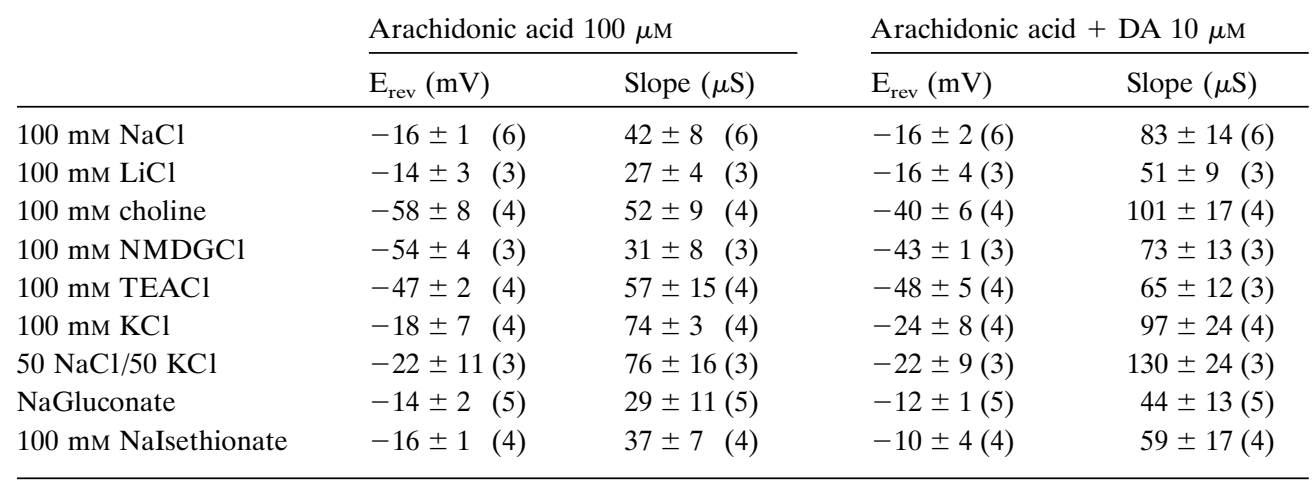

Data for subtracted current-voltage relations $I_{\mathrm{AA}}-I_{\text {control }}$ and $I_{\mathrm{AA}}+\mathrm{DA}-I_{\text {control }}$ in different external solutions (pH 8.3).

Data presented as mean \pm SEM. Number of oocytes recorded under each condition are denoted in parentheses.

The AA-stimulated conductance was shown to be a nonselective cation current because ion substitutions for $\mathrm{Na}^{+}$shifted the reversal potential toward the potassium equilibrium potential. These results are similar to ion permeation in other nonselective cation channels in neurons such as tachykinin-activated cation channels (Inoue et al., 1995) and cAMP-gated channels in olfactory neurons (Balasubramanian et al., 1995). Although the AAstimulated conductance was not selectively permeable to protons, protons did reduce the amplitude of the conductance. In addition, $\mathrm{D}_{2} \mathrm{O}$-substituted solutions blocked the AA + DA-stimulated currents without a shift in the reversal potentials, as expected for nonselective cation conductances where protons bind with high affinity within the pore and inhibit the flow of other ions (Landau et al., 1981; Lewis, 1984; Hille, 1992). Changing the $\mathrm{pH}$ in the range of $\mathrm{pH} 6.8$ to $\mathrm{pH} 8.3$ should not affect the ionization of DA or cocaine molecules as they have $\mathrm{p} K_{a}$ values of 8.86 and 8.5, respectively (Xu and Reith, 1996; Berfield et al., 1999). These studies determined that $\mathrm{pH}$-related differences in binding of DA and the DAT inhibitors, cocaine and WIN 35,428, were attributable to an action of protons on the transporter itself, not to different protonation states of the compounds (Xu and Reith, 1996; Berfield et al., 1999).

\section{AA interactions with DA and cocaine}

Another interesting observation is that the amplitudes of the AA-elicited currents are dependent on the temporal sequence of drug application. Preapplication of DA or cocaine reduced the amplitude of the AA currents. These results imply that both DA and cocaine interfere with the action of AA either by binding to overlapping sites or inducing conformations in DAT that are less sensitive to AA. This is most clearly illustrated with cocaine. Preapplication of cocaine blocks the AA-induced conductance, whereas postapplication of cocaine has no effect on the AA current, suggesting the binding site for cocaine has become at least partially inaccessible. On the other hand, preapplication of dopamine reduces, and postapplication potentiates the AAinduced current. The reversal potentials for the AA-stimulated current and the AA + DA current were similar in all ionic conditions tested, suggesting that AA and DA modulate the same conductance in a $\mathrm{Na}^{+}$- and $\mathrm{Cl}^{-}$-independent manner. Therefore, in the presence of AA, DA binding may potentiate the AAelicited conductance by producing a conformational change in the transporter that results in an increased probability of opening or increased pore diameter of the AA-activated nonselective cation conductance. Alternatively, DA may act at an additional site distinct from that associated with transport or leak blockade. In either case, it is clear that DA binds to the transporter in a manner that does not depend on substrate translocation.

\section{Activation by AA is direct}

A variety of ion channels and transporters are directly modulated by fatty acids. For example, AA and other fatty acids have been shown to inhibit $\mathrm{Na}^{+}$channels (Fraser et al., 1993; Bendahhou et al., 1997), $\mathrm{Ca}^{2+}$ channels (Schmitt and Meves, 1995), and $\mathrm{K}^{+}$ channels (Bogdanov et al., 1998). AA can activate voltageactivated $\mathrm{K}^{+}$channels directly (Ordway et al., 1989; Kim et al., 1995) or indirectly via lipoxygenase metabolites (Piomelli et al., 1987; Kurachi et al., 1989; Vaughan et al., 1997). In addition, AA has been shown to stimulate NMDA receptor currents (Miller et al., 1992) and a nonselective cation conductance in Necturus (Mulvaney and Parsons, 1995). Initial studies looking at AA inhibition of glutamate uptake hypothesized that AA intercalation within the membrane altered the conformation of the transporter (Chan et al., 1983; Barbour et al., 1989). However, other studies observed that AA inhibits transport of glutamate in brain synaptosomes and astrocytes (Chan et al., 1983; Volterra et al.,

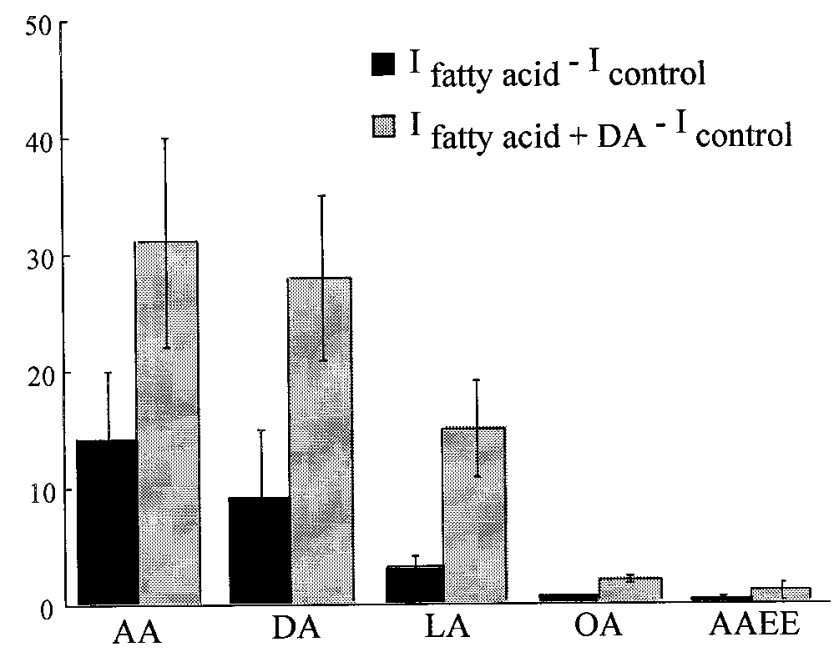

Figure 4. Effects of other fatty acids (PUFAs) on hDAT-expressing oocytes. Bar graph showing the effects of $100 \mu \mathrm{M}$ of each fatty acid on four or five hDAT-expressing oocytes. Data are expressed as mean slope \pm SEM (in microseimans) induced by the fatty acid as determined by subtraction of currents $I_{\text {fatty acid }}-I_{\text {control }}$ (solid bars) and $I_{\text {fatty acid }+ \text { DA }}-$ $I_{\text {control }}$ (hatched bars). 
1992a; Volterra et al., 1994) by binding directly to the transporter in the water phase, not via alterations in the phospholipids surrounding the transporter (Trotti et al., 1995). Similarly, potentiation of the NMDA receptor by AA appears to be via direct binding of AA to the receptor with a specific putative fatty acid binding domain (Miller et al., 1992; Petrou et al., 1993).

Several lines of evidence suggest that AA currents in hDATexpressing oocytes were induced by a direct action of AA. First, inhibitors of the AA second messenger pathways NDGA and ETYA do not inhibit the effects of AA. ETYA, an AA analog that cannot be metabolized by epoxygenases, lipoxygenases, and cyclooxygenases (Salari et al., 1984; Capdevila et al., 1988), stimulates the nonselective cation conductance alone, suggesting that AA metabolites are not necessary for the modulation of DAT by AA. Second, the inactive analog of AA, arachidonic acid ethyl ester, has the same nonspecific effects on membrane fluidity as AA, yet is unable to elicit currents. Third, inhibitors of the $\mathrm{Na}^{+} / \mathrm{K}^{+}$-ATPase and various other ion exchangers that would contribute to a nonselective cation flux across the membrane do not alter the AA-stimulated conductance. Finally, other unsaturated fatty acids that do not activate protein kinase $\mathrm{C}$ can stimulate the nonselective cation conductance with a rank order of potency based on their degree of unsaturation. Thus, it seems likely that AA binds to specific sites and stabilizes specific conformations of the transporter.

\section{Physiological relevance}

DA neurons in the midbrain have dense projections to the striatum, and concentrations of DAT are high in this area (Ciliax et al., 1995; Nirenberg et al., 1996). Several studies have shown that excitatory actions of neurotransmitters including DA can stimulate the release of AA in the striatum (Dumuis et al., 1990; Petitet et al., 1995; Tencé et al., 1995). Dopamine release and activation of D2 receptors (Piomelli et al., 1991; Schinelli et al., 1994) have been shown to stimulate the production of AA in striatal neurons while D1 activation inhibits AA release (Schinelli et al., 1994). These studies suggest that the complex regulation of AA may be an important system in DA neurons. It is not known whether hDAT-mediated currents contribute to the electrical properties of DAT neurons, but AA stimulation of an inward current associated with hDAT may be sufficient to produce significant local depolarization of nerve terminals. Such local depolarization by activation of neurotransmitter transporters has been shown to activate voltage-dependent calcium channels (Haugh-Scheidt et al., 1995; Villalobos and García-Sancho, 1995). Thus, in addition to the potential myriad of effects produced by AA on neurons, the effects of AA on DAT may also alter neuronal signaling.

\section{REFERENCES}

Attwell D, Miller B, Sarantis M (1993) Arachidonic acid as a messenger in the central nervous system. Semin Neurosci 5:159-169.

Balasubramanian S, Lynch JW, Barry PH (1995) The permeation of organic cations through cAMP-gated channels in mammalian olfactory receptor neurons. J Membr Biol 146:177-191.

Barbour B, Szatkowski M, Ingledew N, Attwell D (1989) Arachidonic acid induces a prolonged inhibition of glutamate uptake into glial cells. Nature 342:918-920.

Bendahhou S, Cummins TR, Agnew WS (1997) Mechanism of modulation of the voltage-gated skeletal and cardiac muscle sodium channels by fatty acids. Am J Physiol 272:C592-C600.

Berfield JL, Wang LC, Reith MEA (1999) Which form of dopamine is the substrate for the human dopamine transporter: the cationic or the uncharged species? J Biol Chem 274:4876-4882.

Bogdanov KY, Spurgeon HA, Vinogradova TM, Lakatta EG (1998)
Modulation of the transient outward current in adult rat ventricular myocytes by polyunsaturated fatty acids. Am J Physiol 274:H571-H579.

Capdevila J, Gil L, Orellana M, Marnett LJ, Mason JI, Yadagiri P, Falck JR (1988) Inhibitors of cytochrome P-450-dependent arachidonic acid metabolism. Arch Biochem Biophys 261:257-263.

Cass WA, Gerhardt GA (1994) Direct in vivo evidence that D2 dopamine receptors can modulate dopamine uptake. Neurosci Lett 176:259-263.

Chan PH, Kerlan R, Fishman RA (1983) Reductions of g-aminobutyric acid and glutamate uptake and $\left(\mathrm{Na}^{+}+\mathrm{K}^{+}\right)$-ATPase activity in brain slices and synaptosomes by arachidonic acid. J Neurochem 40:309-316.

Ciliax BJ, Heilman C, Demchyshyn LL, Pristupa ZB, Ince E, Hersch SM, Niznik HB, Levey AI (1995) The dopamine transporter: immunochemical characterization and localization in brain. J Neurosci 15:1714-1723.

Costa PF, Emilio MG, Fernandes PL, Ferreira HG, Ferreira KG (1989) Determination of ionic permeability coefficients of the plasma membrane of Xenopus Laevis oocytes under voltage clamp. J Physiol (Lond) 413:199-211.

DeFelice LJ, Blakely RD (1996) Pore models for transporters? Biophys J 70:579-580.

Dumuis A, Sebben M, Haynes L, Pin J-P, Bockaert J (1988) NMDA receptors activate the arachidonic acid cascade system in striatal neurons. Nature 336:68-70.

Dumuis A, Pin JP, Oomagari K, Sebben M, Bockaert J (1990) Arachidonic acid released from striatal neurons by joint stimulation of ionotropic and metabotropic quisqualate receptors. Nature 347:182-184.

Fairman WA, Sonders MS, Murdoch GH, Amara SG (1998) Arachidonic acid elicits a substrate-gated proton current associated with the glutamate transporter EAAT4. Nat Neurosci 1:105-113.

Fraser DD, Hoehn K, Weiss S, MacVicar BA (1993) Arachidonic acid inhibits sodium currents and synaptic transmission in cultured striatal neurons. Neuron 11:633-644.

Gu H, Wall SC, Rudnick G (1994) Stable expression of biogenic amine transporters reveals differences in inhibitor sensitivity, kinetics, and ion dependence. J Biol Chem 269:7124-7130.

Haugh-Scheidt L, Malchow RP, Ripps H (1995) GABA transport and calcium dynamics in horizontal cells from the skate retina. J Physiol (Lond) 488:565-576.

Hille B (1992) Ionic channels of excitable membranes, Ed 2. Sunderland: Sinauer.

Inoue K, Nakazawa K, Inoue K, Fujimori K (1995) Nonselective cation channels coupled with tachykinin receptors in rat sensory neurons. J Neurophysiol 73:736-743.

Itzhak Y, Ali SF (1996) The neuronal nitric oxide synthase inhibitor, 7-nitroindazole, protects against methamphetamine-induced neurotoxicity in vivo. J Neurochem 67:1770-1773.

Kilty JE, Lorang D, Amara SG (1991) Cloning and expression of a cocaine-sensitive rat dopamine transporter. Science 254:578-579.

Kim D, Sladek CD, Aguado-Velasco C, Mathiasen JR (1995) Arachidonic acid activation of a new family of $\mathrm{K}^{+}$channels in cultured rat neuronal cells. J Physiol (Lond) 484:643-660.

Krueger BK (1990) Kinetics and block of dopamine uptake in synaptosomes from rat caudate nucleus. J Neurochem 55:260-267.

Kurachi Y, Ito H, Sugimoto T, Shimizu T, Miki I, Ui M (1989) Arachidonic acid metabolites as intracellular modulators of the $G$ proteingated cardiac $\mathrm{K}^{+}$channel. Nature 338:360-362.

L'hirondel M, Chéramy A, Godeheu G, Glowinski J (1995) Effects of arachidonic acid on dopamine synthesis, spontaneous release, and uptake in striatal synaptosomes from the rat. J Neurochem 64:1406-1409.

Landau EM, Gavish B, Nachshen DA, Lotan I (1981) pH dependence of the acetylcholine receptor channel. J Gen Physiol 77:647-666.

Lester HA, Mager S, Quick MW, Corey JL (1994) Permeation properties of neurotransmitter transporters. Annu Rev Pharmacol Toxicol 34:219-249.

Lewis CA (1984) Deuterium oxide effects on frog endplate channels. Biophys J 45:16-18.

McElvain JS, Schenk JO (1992) A multisubstrate mechanism of striatal dopamine uptake and its inhibition by cocaine. Biochem Pharmacol 43:2189-2199.

Meiergerd SM, Patterson TA, Schenk JO (1993) $\mathrm{D}_{2}$ receptors may modulate the function of the striatal transporter for dopamine: kinetic evidence from studies in vitro and in vivo. J Neurochem 61:764-767. 
Miller B, Sarantis M, Traynelis SF, Attwell D (1992) Potentiation of NMDA receptor currents by arachidonic acid. Nature 355:722-725.

Mulvaney JM, Parsons RL (1995) Arachidonic-acid-activated membrane conductances in dissociated cardiac parasympathetic neurons from Necturus. J Neurophysiol 74:1621-1627.

Nirenberg MJ, Vaughan RA, Uhl GR, Kuhar MJ, Pickel VM (1996) The dopamine transporter is localized to dendritic and axonal plasma membranes of nigrostriatal dopaminergic neurons. J Neurosci 16:436-447.

Ordway RW, Walsh Jr JV, Singer JJ (1989) Arachidonic acid and other fatty acids directly activate potassium channels in smooth muscle cells. Science 244:1176-1179.

Ordway RW, Singer JJ, Walsh Jr JV (1991) Direct regulation of ion channels by fatty acids. Trends Neurosci 14:96-100.

Petitet F, Blanchard JC, Doble A (1995) Effects of AMPA receptor modulators on the production of arachidonic acid from striatal neurons. Eur J Pharmacol 291:143-151.

Petrou S, Ordway RW, Singer JJ, Walsh Jr JV (1993) A putative fatty acid-binding domain of the NMDA receptor. Trends Biochem Sci 18:41-42.

Piomelli D, Volterra A, Dale N, Siegelbaum SA, Kandel ER, Schwartz JH, Belardetti F (1987) Lipoxygenase metabolites of arachidonic acid as second messenger for presynaptic inhibition of Aplysia sensory cells. Nature 328:38-43.

Piomelli D, Pilon C, Giros B, Sokoloff P, Martres M-P, Schwartz J-C (1991) Dopamine activation of the arachidonic acid cascade as a basis for $D_{1} / D_{2}$ receptor synergism. Nature 353:164-167.

Pogun S, Baumann MH, Kuhar MJ (1994) Nitric oxide inhibits $\left[{ }^{3} \mathrm{H}\right]$ dopamine uptake. Brain Res 641:83-91.

Quick MW, Lester HA (1994) Methods for expression of excitability proteins in Xenopus oocytes. Methods Neurosci 19:261-279.

Salari H, Braquet P, Borgeat P (1984) Comparative effects of indomethacin, acetylenic acids, 15-HETE, nordihydroguaiaretic acid and BW755c on the metabolism of arachidonic acid in human leukocytes and platelets. Prostaglandins Leukot Med 13:53-60.

Schinelli S, Paolillo M, Corona GL (1994) Opposing actions of $\mathrm{D}_{1^{-}}$and $\mathrm{D}_{2}$-dopamine receptors on arachidonic acid release and cyclic AMP production in striatal neurons. J Neurochem 62:944-949.

Schmitt H, Meves H (1995) Modulation of neuronal calcium channels by arachidonic acid and related substances. J Membr Biol 145:233-244.

Sonders MS, Amara SG (1996) Channels in transporters. Curr Opin Neurobiol 6:294-302.

Sonders MS, Zhu S-J, Zahniser NR, Kavanaugh MP, Amara SG (1997) Multiple ionic conductances of the human dopamine transporter: The actions of dopamine and psychostimulants. J Neurosci 17:960-974.
Tencé M, Murphy N, Cordier J, Prémont J, Glowinski J (1995) Synergistic effects of acetylcholine and glutamate on the release of arachidonic acid from cultured striatal neurons. J Neurochem 64:1605-1613.

Trotti D, Volterra A, Lehre KP, Rossi D, Gjesdal O, Racagni G, Danbolt NC (1995) Arachidonic acid inhibits a purified and reconstituted glutamate transporter directly from the water phase and not via the phospholipid membrane. J Biol Chem 270:9890-9895.

Tzingounis AV, Lin C-L, Rothstein JD, Kavanaugh MP (1998) Arachidonic acid activates a proton current in the rat glutamate transporter EAAT4. J Biol Chem 273:17315-17317.

Vaughan CW, Ingram SL, Connor MA, Christie MJ (1997) How opioids inhibit GABA-mediated neurotransmission. Nature 390: 611-614.

Villalobos C, García-Sancho J (1995) Glutamate increases cytosolic calcium in $\mathrm{GH}_{3}$ pituitary cells acting via a high-affinity glutamate transporter. FASEB J 9:815-819.

Volterra A, Trotti D, Cassutti P, Tromba C, Galimberti R, Lecchi P, Racagni G (1992a) A role for the arachidonic acid cascade in fast synapse modulation: ion channels and transmitter uptake systems as target proteins. Adv Exp Med Biol 318:147-158.

Volterra A, Trotti D, Cassutti P, Tromba C, Salvaggio A, Melcangi RC, Racagni G (1992b) High sensitivity of glutamate uptake to extracellular free arachidonic acid levels in rat cortical synaptosomes and astrocytes. J Neurochem 59:600-606.

Volterra A, Trotti D, Racagni G (1994) Glutamate uptake is inhibited by arachidonic acid and oxygen radicals via two distinct and additive mechanisms. Mol Pharmacol 46:986-992.

Xu C, Reith MEA (1996) Modeling of the $\mathrm{pH}$ dependence of the binding of WIN 35,428 to the dopamine transporter in rat striatal membranes: is the bioactive form positively charged or neutral? J Pharmacol Exp Ther 278:1340-1348.

Zerangue N, Arriza JL, Amara SG, Kavanaugh MP (1995) Differential modulation of human glutamate transporter subtypes by arachidonic acid. J Biol Chem 270:6433-6435.

Zhang L, Reith MEA (1996) Regulation of the functional activity of the human dopamine transporter by the arachidonic acid pathway. Eur J Pharmacol 315:345-354.

Zhang L, Coffey LL, Reith MEA (1997) Regulation of the functional activity of the human dopamine transporter by protein kinase $\mathrm{C}$. Biochem Pharmacol 53:677-688.

Zhu S-J, Kavanaugh MP, Sonders MS, Amara SG, Zahniser NR (1997) Activation of protein kinase $\mathrm{C}$ inhibits uptake, currents and binding associated with the human dopamine transporter expressed in Xenopus oocytes. J Pharmacol Exp Ther 282:1358-1365. 